\title{
Anticoagulant Therapy in a Pregnant Woman with May-Thurner Syndrome
}

\author{
Masaki Goto ${ }^{1}$, Shin-ichiro Miura ${ }^{1,2}$, Tomohiko Yamamoto ${ }^{1}$, Yusuke Fukuda ${ }^{1}$, \\ Takashi Kuwano ${ }^{1}$, Ibuki Kimura ${ }^{3}$, Ayako Sanui ${ }^{3}$, Shingo Miyamoto ${ }^{3}$ and Keijiro Saku ${ }^{1,2}$
}

\begin{abstract}
A 39-year-old woman with a 9-week abdominal pregnancy noted pain in her lower abdomen and left leg. Since successive thrombi were observed extending from the left common iliac vein to the popliteal vein along with a thrombus in the left pulmonary artery, we diagnosed her with pulmonary thromboembolism with deep venous thrombosis (DVT). May-Thurner syndrome may have contributed to DVT in the left leg when the left iliac vein was compressed by the right iliac artery. She underwent anticoagulant therapy with heparin, followed by the subcutaneous injection of heparin at home after discharge. We herein report the case of a pregnant woman with May-Thurner syndrome who safely gave birth.
\end{abstract}

Key words: May-Thurner syndrome, anticoagulant therapy, pregnancy, pulmonary thromboembolism, venous thrombosis

(Intern Med 55: 59-62, 2016)

(DOI: 10.2169/internalmedicine.55.5215)

\section{Introduction}

May-Thurner syndrome occurs when the left iliac vein is compressed by the right iliac artery, which increases the risk of deep vein thrombosis (DVT) in the left leg. This type of deep vein thrombosis was reported by May and Thurner in 1957 (1). The incidence of May-Thurner syndrome has been reported to range from $18 \%$ to $49 \%$ among patients with left-sided lower extremity DVT (2). It has also been reported that May-Thurner syndrome is present in over $20 \%$ of the population; however, most patients do not show symptoms because of the collateral circulation in the iliac vein. Despite the relatively high incidence of this anatomical variation, the clinical prevalence of May-Thurner syndromerelated DVT is surprisingly low, and it reportedly occurs in only $2 \%$ to $3 \%$ of all cases of DVT in the left leg (3).

Although some previous case reports have described MayThurner syndrome in pregnant women, as in our present case, there is no established treatment. Therefore, we report the present case, in which we experienced a successful therapeutic strategy, compared to previous cases of May-
Thurner syndrome.

\section{Case Report}

A 39-year-old woman with a 9-week abdominal pregnancy noted pain in her lower abdomen and left leg and visited our hospital. She was a full-time housewife. This was her first pregnancy, and she did not have a history of miscarriage. She did not receive any infertility treatment. The results of a physical examination of height, weight, body temperature, blood pressure, heart rate and $\mathrm{SpO}_{2}$ on admission were $153 \mathrm{~cm}, 44.6 \mathrm{~kg}, 36.9^{\circ} \mathrm{C}, 99 / 68 \mathrm{mmHg}, 83 / \mathrm{min}$ and $99 \%$, respectively, and abnormal findings revealed redness and swelling of the left thigh. No abnormalities were seen on an electrocardiogram or chest X-ray obtained on admission (Fig. 1). Since the laboratory data showed increased white blood cell and D-dimer levels in the blood, we performed ultrasonography of the leg veins to assess suspected left deep venous thrombosis (Table). We observed a thrombus that was continuous from the external iliac vein to the popliteal vein and subsequently made a diagnosis of left DVT. To evaluate the potential for pulmonary thromboem-

\footnotetext{
${ }^{1}$ Department of Cardiology, Fukuoka University School of Medicine, Japan, ${ }^{2}$ Department of Molecular Cardiovascular Therapeutics, Fukuoka University School of Medicine, Japan and ${ }^{3}$ Department of Obstetrics and Gynecology, Fukuoka University School of Medicine, Japan Received for publication February 24, 2015; Accepted for publication June 30, 2015

Correspondence to Dr. Shin-ichiro Miura, miuras@cis.fukuoka-u.ac.jp
} 


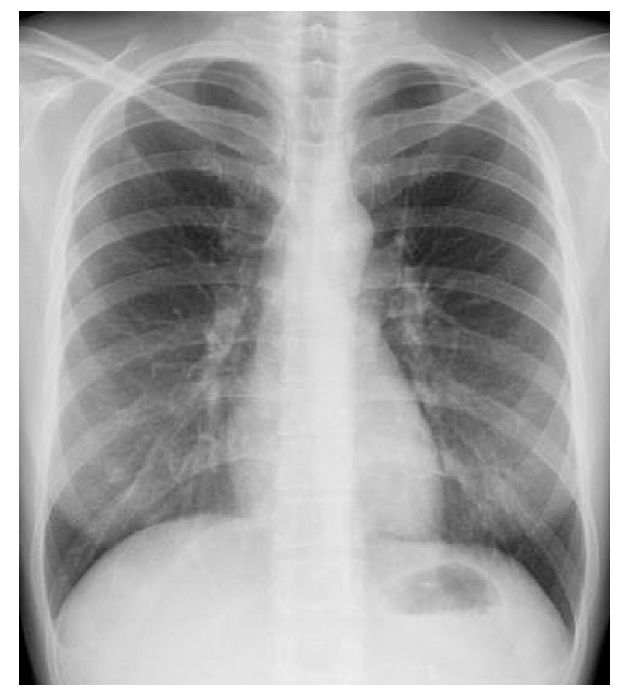

Figure 1. Chest X-ray on admission.

bolism in DVT, we performed contrast-enhanced computed tomography (CT) after obtaining informed consent. We observed a successive thrombus extending from the left common iliac vein and further recognized a filling defect in the left pulmonary artery. We therefore made a diagnosis of pulmonary thromboembolism and DVT (Fig. 2). These findings may have been due to May-Thurner syndrome because the thrombus in a deep vein in the left leg occurred due to compression of the left common iliac vein under pressure caused by the right common iliac artery and a vertebral body (Fig. 3). Furthermore, dehydration resulting from hyperemesis was regarded as a cause. On the other hand, there were no abnormal findings on various blood tests suggestive of a predisposition to thrombus development (Table).

After admission, we inserted a temporary inferior vena cava filter from the internal jugular vein to prevent further progression of pulmonary embolism and started a continuous infusion of heparin, setting a goal of APTT of 1.5-2 fold versus that at admission. Although the thrombus in the left common iliac vein remained, as assessed on ultrasound, we judged that the thrombosis had stabilized for the following reasons. First, the patient's symptoms disappeared. Second, the disappearance of inflammation and normalization of the D-dimer level were confirmed on blood tests. Third, the thrombus was reduced in size and the residual thrombus tissue was organized on ultrasound. Therefore, we removed the temporary inferior vena cava filter after two weeks. We subsequently started to inject heparin subcutaneously and continued this treatment at discharge. The target value of APTT was set 1.5 -fold higher than the value observed on admission (approximately 25,000 units/day of heparin). We did not use warfarin based on the consideration of possible adverse effects on the fetus. As an outpatient, the patient continued her pregnancy without any problems and gave birth to a healthy baby at 38 weeks via vaginal delivery. A CT assessment performed after birth showed that the thrombus was still present, and warfarin therapy was started.
Table. Blood Test.

\begin{tabular}{|c|c|c|c|c|c|}
\hline \multicolumn{2}{|c|}{ WBC $9,900 / \mu \mathrm{L}$} & TP & $6.8 \mathrm{~g} / \mathrm{dL}$ & LDL-C & $102 \mathrm{mg} / \mathrm{dL}$ \\
\hline \multicolumn{2}{|c|}{ RBC $398 \times 10^{4} / \mu \mathrm{L}$} & ALB & $4.4 \mathrm{~g} / \mathrm{dL}$ & HDL-C & $56 \mathrm{mg} / \mathrm{dL}$ \\
\hline \multicolumn{2}{|c|}{$11.5 \mathrm{~g} / \mathrm{dL}$} & BUN & $12 \mathrm{mg} / \mathrm{dL}$ & TG & $68 \mathrm{mg} / \mathrm{dL}$ \\
\hline \multirow{2}{*}{$\begin{array}{l}\text { Ht } \\
\text { Plt }\end{array}$} & $33.4 \%$ & $\mathrm{Cr}$ & $0.50 \mathrm{mg} / \mathrm{dL}$ & & \\
\hline & \multirow[t]{2}{*}{$17.1 \times 10^{4} / \mu \mathrm{L}$} & $\mathrm{Na}$ & $134 \mathrm{mEq} / \mathrm{L}$ & F-T3 & $2.88 \mathrm{pg} / \mathrm{mL}$ \\
\hline & & $\mathrm{K}$ & $3.4 \mathrm{mEq} / \mathrm{L}$ & F-T4 & $1.20 \mathrm{ng} / \mathrm{dL}$ \\
\hline PT-INR & 1.12 & $\mathrm{Cl}$ & $98 \mathrm{mEq} / \mathrm{L}$ & TSH & $0.39 \mu \mathrm{IU} / \mathrm{mL}$ \\
\hline APTT & $30.2 \mathrm{sec}$ & AST & $14 \mathrm{IU} / \mathrm{L}$ & \multicolumn{2}{|c|}{ NT-pBNP $71 \mathrm{pg} / \mathrm{mL}$} \\
\hline ATIII & $109 \%$ & ALT & $13 \mathrm{IU} / \mathrm{L}$ & $\mathrm{RF}^{* 1}$ & $(-)$ \\
\hline FDP & $>120 \mu \mathrm{g} / \mathrm{mL}$ & LDH & $213 \mathrm{IU} / \mathrm{L}$ & $\mathrm{LA}^{* 2}$ & $(-)$ \\
\hline D-dimer & $>60 \mu \mathrm{g} / \mathrm{mL}$ & CRP & $0.03 \mathrm{mg} / \mathrm{dL}$ & $\mathrm{aCL}^{* 3}$ & $(-)$ \\
\hline Protein C & $96 \%$ & Glu & $98 \mathrm{mg} / \mathrm{dL}$ & & \\
\hline Protein $\mathrm{S}$ & $50 \%$ & $\mathrm{HbAlc}$ & $5.5 \%$ & & \\
\hline
\end{tabular}

\section{Discussion}

We encountered a pregnant women with May-Thurner syndrome who safely gave birth despite DVT. May-Thurner syndrome is caused when the left iliac vein is compressed by the right iliac artery, which increases the risk of DVT in the left leg (4).

There are several options for DVT treatment: anticoagulant therapy, catheter-directed thrombolytic therapy, angioplasty and stenting $(5,6)$. The goal of treatment is to reduce symptoms and the risk of complications. On the other hand, the goal of surgical treatment is to remove the thrombus. Before any treatments are selected, it is important to evaluate the potential benefits, risks and side effects. Historically, several surgical procedures have been used to correct compression, including venovenous bypass with an autologous vein, the creation of a tissue sling to elevate the overriding right iliac artery, retropositioning of the iliac artery and excision of the intraluminal spur via patch venoplasty. Recently, an important strategy has been to provide endovascular treatment or a combination of endovascular and surgical treatment $(5,6)$. A recent report showed that these treatments decrease the incidence of DVT, known as postthrombotic syndrome (PTS), and venous obstruction compared with systemic anticoagulation $(\mathrm{RR}=0.19,95 \% \mathrm{CI}$ 0.07 to 0.48$)(7,8)$.

Although there are some reports showing that endovascular treatment is the only option for May-Thurner syndrome in pregnant women, pregnant women are usually at a higher risk of complications, such as in-stent restenosis (9). Therefore, the treatment should be selected to suit the patient (10-13). The present case involved a pregnant woman, and both she and her husband hoped to continue the pregnancy. Therefore, we considered two main points when selecting the treatment: the adverse effect of radiation on the fetus and the adverse effect of medications on the fetus. As for the adverse effect of radiation on the fetus, we used as few examinations as possible based on the potential for teratogenicity and central neuropathy according to carcinogenicity and hereditary influences $(14,15)$. As for the adverse ef- 

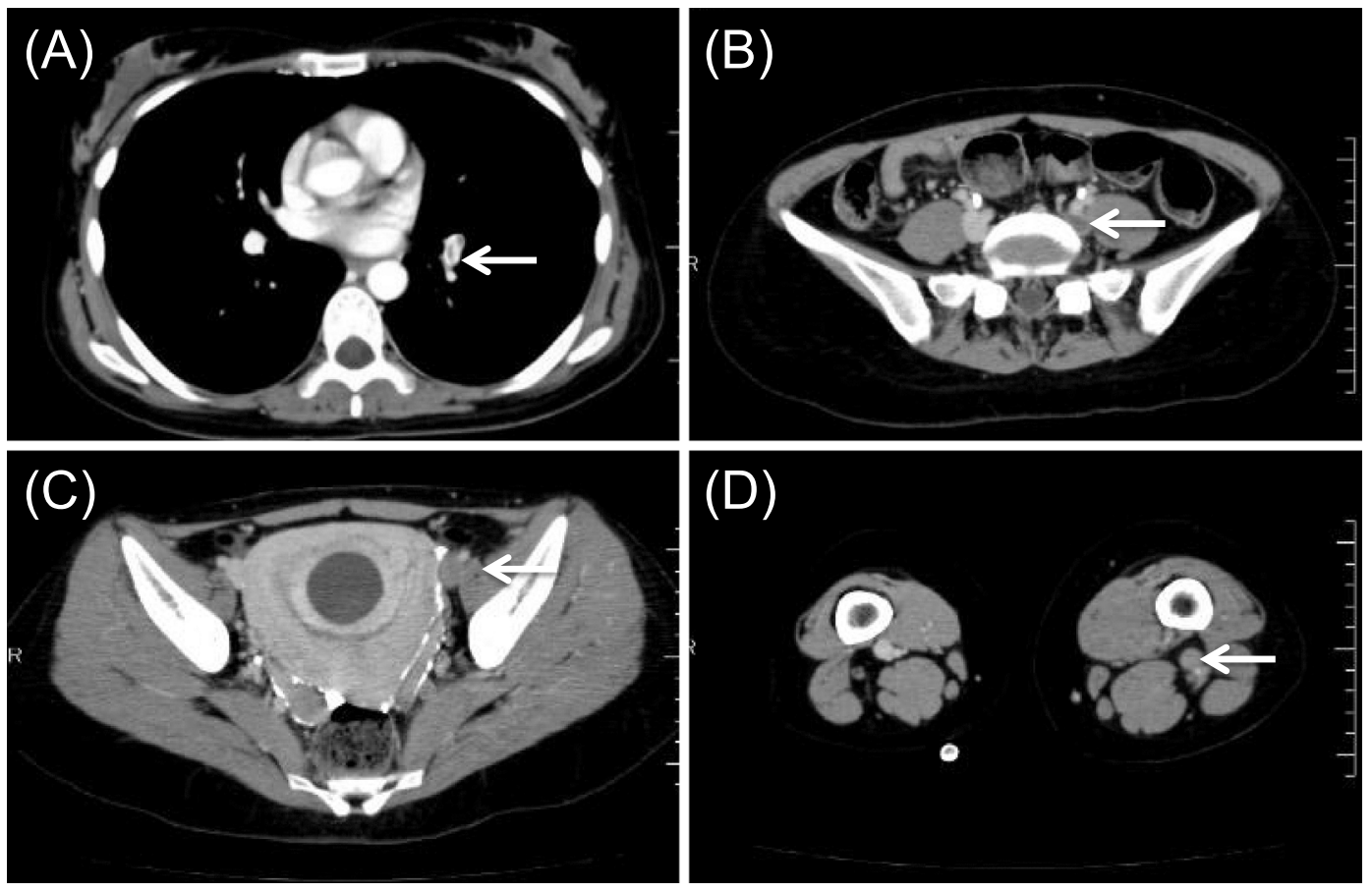

Figure 2. Contrast CT images. (A) The filling defect in the left pulmonary artery. (B)-(D) A successive thrombus extending from the left common iliac vein.

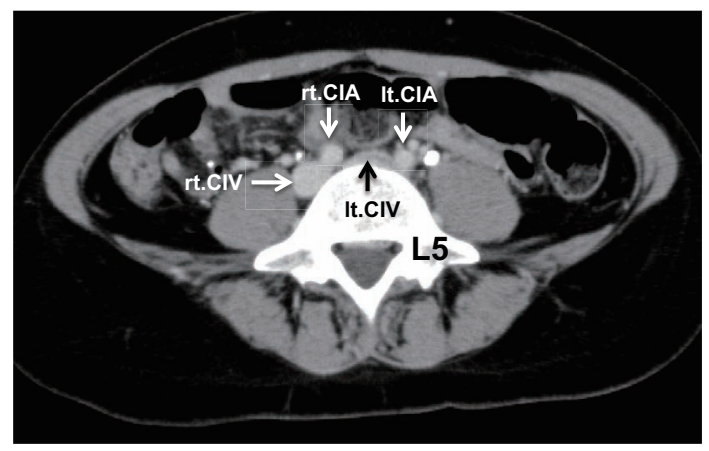

Figure 3. May-Thurner syndrome. A CT image shows the left common iliac vein (lt. CIV) compressed by the right common iliac artery (rt. CIA).

fect of medications on the fetus, we used heparin. Heparin has fewer complications than warfarin and is easy to use, according to many past reports in pregnant women (16). Ultimately, the patient gave birth to a healthy baby via vaginal delivery. DVT generally leads to severe pulmonary embolism and is potentially fatal. Therefore, we considered the need for Cesarean section. However, after careful consideration, we selected vaginal delivery because of the lower risk for fetus. In addition, delivery may carry a higher risk of bleeding than thrombosis formation associated with the discontinuation of heparin. In such rare cases, physicians should carefully consider the risks to the fetus and mother, and it is important to select a suitable treatment in each case.

In conclusion, we experienced a case in which we observed the optimal choice of anticoagulant therapy in a pregnant woman with May-Thurner syndrome.
The authors state that they have no Conflict of Interest (COI).

\section{References}

1. May R, Thurner J. The cause of the predominantly sinistral occurrence of thrombosis of the pelvic veins. Angiology 8: 419-427, 1957.

2. Kasirajan K, Gray B, Ouriel K. Percutaneous Angio-Jet thrombectomy in the management of extensive deep venous thrombosis. $\mathrm{J}$ Vasc Interv Radiol 12: 179-185, 2001.

3. O'Sullivan GJ, Semba CP, Bittner CA, et al. Endovascular management of iliac vein compression (May-Thurner) syndrome. J Vasc Interv Radiol 11: 823-836, 2000.

4. Virchow R. Ueber die Erweiterung kleinerer Gefäfse. Arch Pathol Anat Physiol Klin Med 3: 427-462, 1851 (in German).

5. Al-Nouri O, Milner R. May-Thurner syndrome. Vasc Dis Mgt 3: 53-56, 2011.

6. Herrera S, Comerota AJ, Thakur S, et al. Managing iliofemoral deep venous thrombosisof pregnancy with a strategy of thrombus removal is safe and avoids post-thrombotic morbidity. J Vasc Surg 59: 456-464, 2014.

7. Casey ET, Murad MH, Zumaeta-Garcia M, et al. Treatment of acute iliofemoral deep vein thrombosis. J Vasc Surg 55: 14631473, 2012.

8. DeStephano CC, Werner EF, Holly BP, Lessne ML. Diagnosis and management of iliac vein thrombosis in pregnancy resulting from May-Thurner syndrome. J Parinatol 34: 566-568, 2014.

9. Olivier H, Pierre B, Dominique A, Mourad B, Yves SA. Management of pregnancy in women with previous left ilio-caval stenting. J Vasc Surg 50: 355-359, 2009.

10. Moudgill N, Hager E, Gonsalves C, Larson R, Lombardi J, DiMuzio P. May-Thurner syndrome: case report and review of the literature involving modern endovascular therapy. Vascular 17: 330-335, 2009.

11. Suwanabol PA, Tefera G, Schwarze ML. Syndromes associated with the deep veins: phlegmasia cerulea dolens, May-Thurner syn- 
drome, and nutcracker syndrome. Perspect Vasc Surg Endovasc Ther 22: 223-230, 2010.

12. Palma E, Esperon R. Vein transplants and grafts in the surgical treatment of the postphlebitic syndrome. J Cardiovasc Surg (Torino) 1: 94-107, 1960.

13. Cockett FB, Thomas ML. The iliac compression syndrome. Br J Surg 52: 816-821, 1965.
14. ICRP. Pregnancy and medical radiateon. ICRP Publication 84. Ann ICRP 30 (1), 2000.

15. Brent RL. The effect of embryonic and fetal exposure to X-ray, microwaves, and ultrasound: counseling the pregnant and nonpregnant patient about these risks. Semin Oncol 16: 347-368, 1989.

16. Hall JG, Pauli RM, Wilson KM. Maternal and fetal sequel of anticoagulation during pregnancy. Am J Med 68: 122-140, 1980.

(C) 2016 The Japanese Society of Internal Medicine http://www.naika.or.jp/imonline/index.html 